\title{
Ultimate Bearing Capacity of Strip Foundations in Unsaturated Soils considering the Intermediate Principal Stress Effect
}

\author{
Qing Yan $\mathbb{D}^{1},{ }^{1}$ Junhai Zhao $\mathbb{D}^{1},{ }^{1}$ Changguang Zhang $\mathbb{D}^{1},{ }^{1}$ and Jintai Wang $\mathbb{D}^{2}$ \\ ${ }^{1}$ School of Civil Engineering, Chang'an University, Xi'an 710061, China \\ ${ }^{2}$ Geosyntec Consultants, 9211 Arboretum Pkwy., Suite 200, Richmond, VA 233236, USA
}

Correspondence should be addressed to Changguang Zhang; zcg1016@163.com

Received 24 March 2020; Revised 20 July 2020; Accepted 18 August 2020; Published 4 September 2020

Academic Editor: Xiaodong Hu

Copyright (c) 2020 Qing Yan et al. This is an open access article distributed under the Creative Commons Attribution License, which permits unrestricted use, distribution, and reproduction in any medium, provided the original work is properly cited.

\begin{abstract}
The reasonable determination of ultimate bearing capacity is crucial to an optimal design of shallow foundations. Soils surrounding shallow foundations are commonly located above the water table and are thus in an unsaturated state. The intermediate principal stress has an improving effect on the unsaturated soil strength. In this study, the ultimate bearing capacity formulation of strip foundations in unsaturated soils is presented by using Terzaghi's theory. The unified shear strength equation of unsaturated soils under a plane strain condition is utilized to capture the intermediate principal stress effect. Furthermore, two profiles of matric suction are considered and a hyperbolic function of the friction angle related to matric suction $\left(\varphi^{b}\right)$ is adopted to describe strength nonlinearity. The validity of this study is demonstrated by comparing it with model tests and a theoretical solution reported in the literature. Finally, parameter studies are conducted to investigate the effects of intermediate principal stress, matric suction, and base roughness on the ultimate bearing capacity of strip foundations. Besides, the effect of strength nonlinearity is discussed with two methods representing the angle $\varphi^{\mathrm{b}}$.
\end{abstract}

\section{Introduction}

The ultimate bearing capacity of a foundation denotes the maximum load that foundation soils can withstand [1-3], and its reasonable determination is one of the pivotal parts in foundation designs. Numerous studies about the ultimate bearing capacity of strip foundations are focused on saturated soils [4-8]. However, foundation soils are mostly in an unsaturated state on account of common uses of waterproof and draining measures [9-12]. Using the saturated soil mechanics to calculate the ultimate bearing capacity of foundations in unsaturated soils neglects the strength contribution from matric suction [9-17]. There are several attempts to account for the effect of matric suction in the determination of bearing capacity for shallow foundations within the context of the unsaturated soil mechanics.

Based on Fredlund's two independent stress state variables theory, Oloo et al. [18] derived a formulation of ultimate bearing capacity for strip foundations in unsaturated soils by incorporating the effect of matric suction. Vanapalli and Mohamed [19] performed model tests to measure soil suction, and the result highlighted that matric suction can significantly increase the ultimate bearing capacity of rectangular foundations. Zhao et al. [20] conducted an upper-bound analysis of the ultimate bearing capacity for strip foundations in unsaturated soils under uniform and linear suction profiles, whereas a computer code was required to find optimal results. Oh and Vanapalli $[21,22]$ revealed nonuniform variations of matric suction with depth through a series of model tests for square foundations and conducted an extended finite element analysis by modifying the total stress approach to investigate the ultimate bearing capacity of shallow foundations in unsaturated soils. Vo and Russell [23] presented a slip line solution of ultimate bearing capacity for strip foundations in unsaturated soils where the contribution of matric suction to the effective stress is approximated as a function that varies linearly with depth, while the solution was represented in a 
dimensionless form not the traditional superposition one of three components. Tang et al. [24] established alternative equations of ultimate bearing capacity for strip foundations in unsaturated soils with the effective stress shear strength theory by assuming both uniform and varied suction stress profiles. Mahmoudabadi and Ravichandran [25] defined a coupled geotechnical-hydrological model incorporating site-specific rainfall and water table data to calculate the ultimate bearing capacity of shallow foundations based on unsaturated soil principles, yet the acquisition of site-specific historical hydrological data is difficult. Garakani et al. [26] proposed a new analytical solution for the ultimate bearing capacity of unsaturated soils by introducing a correction factor $C_{f}$, which could satisfactorily predict the measured result of various physical loading tests. However, the correction factor $C_{f}$ is achieved from fitting or backcalculating the existing test results; that is, experimental data are firstly demanded to use this solution.

Note that these above results are based on the Mohr-Coulomb criterion, and hence the intermediate principal stress effect cannot be considered. The ultimate bearing capacity calculation of a strip foundation is often taken as a plane strain problem [1-3]. The plane strain condition signifies a true three-dimensional stress state where soil strength is higher than that under a conventional triaxial compression state. Extensive true triaxial test results of unsaturated soils [27, 28] and predictions of the Drucker-Prager criterion [29] and the unified strength theory $[30,31]$ have confirmed that a conservative result is obtained by utilizing the Mohr-Coulomb criterion without reflecting the influence of intermediate principal stress. Meanwhile, the intermediate principal stress has a marked impact on the strength of saturated soils [32-34]. The unified strength theory proposed by $\mathrm{Yu}$ [30] is a set of failure criteria including or approximating various conventional ones, and the intermediate principal stress effect can be reasonably reflected. On the basis of the unified strength theory [30] and the theory of two independent stress state variables [35], Zhang et al. [36, 37] presented a unified equation for the plane strain shear strength of unsaturated soils to reasonably capture the effect of intermediate principal stress. In addition, the relationship between the unsaturated soil strength and matric suction is nonlinear over a broad range of matric suctions rather than linear ones, and the friction angle related to matric suction $\left(\varphi^{\mathrm{b}}\right)$ varies nonlinearly with increasing matric suction [38-43]. A hyperbolic function of the angle $\varphi^{\mathrm{b}}$ was introduced to exhibit strength nonlinearity of unsaturated soils. Moreover, there are two profiles of matric suction commonly used in engineering practice $[9,10,16,40]$ : one is the matric suction distributing uniformly with depth, and the other is the matric suction decreasing linearly with depth.

The primary objective of this study is to present a formulation of the ultimate bearing capacity for strip foundations in unsaturated soils under uniformly and linearly distributed suctions. The unified shear strength equation of unsaturated soils and a hyperbolic function of the angle $\varphi^{\mathrm{b}}$ are adopted to account for the influences from intermediate principal stress and strength nonlinearity. The validity of the proposed formulation is further verified by comparing with two existing results reported in the literature. Additionally, a parametric study is carried out to study various effects of intermediate principal stress, matric suction and its distribution, strength nonlinearity, and base roughness on the ultimate bearing capacity of strip foundations.

\section{Basic Theories}

2.1. Unified Shear Strength Equation of Unsaturated Soils under Plane Strain Conditions. Shear strength $\tau_{\mathrm{f}}$ for saturated soils using the Mohr-Coulomb criterion is written as

$$
\tau_{\mathrm{f}}=c^{\prime}+\sigma \tan \varphi^{\prime},
$$

where $c^{\prime}$ is the effective cohesion, $\varphi^{\prime}$ is the effective internal friction angle, and $\sigma$ is the effective normal stress.

Shear strength of unsaturated soils based on the theory of two independent stress state variables [35] and the Mohr-Coulomb criterion is expressed as

$$
\tau_{\mathrm{f}}=c^{\prime}+\left(\sigma-u_{\mathrm{a}}\right) \tan \varphi^{\prime}+\left(u_{\mathrm{a}}-u_{\mathrm{w}}\right) \tan \varphi^{\mathrm{b}},
$$

where $\varphi^{\mathrm{b}}$ is the friction angle related to matric suction, $u_{\mathrm{a}}$ is the pore air pressure, $u_{\mathrm{w}}$ is the pore water pressure, $\left(u_{\mathrm{a}}-u_{\mathrm{w}}\right)$ is the matric suction, and $\left(\sigma-u_{\mathrm{a}}\right)$ is the net normal stress. Equation (2) degenerates into equation (1) for saturated soils when $\left(u_{\mathrm{a}}-u_{\mathrm{w}}\right)=0$.

The angle $\varphi^{\mathrm{b}}$ is usually predicted by two methods $[16,40]$. Method I: the relationship between unsaturated soil strength and matric suction is assumed to be linear for an overall suction range, which means that $\varphi^{\mathrm{b}}$ is a small stable value. Method II is divided into two segments: when matric suction is not larger than the air-entry value $\left(u_{\mathrm{a}}-u_{\mathrm{w}}\right)_{\mathrm{b}}, \varphi^{\mathrm{b}}$ is a constant equal to $\varphi^{\prime}$; when matric suction is larger than $\left(u_{\mathrm{a}}-u_{\mathrm{w}}\right)_{\mathrm{b}}, \varphi^{\mathrm{b}}$ decreases continuously as a hyperbolic function. The expression of $\varphi^{\mathrm{b}}$ for Method II is written as

$$
\begin{aligned}
& \varphi^{\mathrm{b}}=\varphi^{\prime}, \quad \text { when }\left(u_{\mathrm{a}}-u_{\mathrm{w}}\right) \leq\left(u_{\mathrm{a}}-u_{\mathrm{w}}\right)_{\mathrm{b}}, \\
& \varphi^{\mathrm{b}}=\varphi^{\prime}-\frac{\left(u_{\mathrm{a}}-u_{\mathrm{w}}\right)-\left(u_{\mathrm{a}}-u_{\mathrm{w}}\right)_{\mathrm{b}}}{m+n\left[\left(u_{\mathrm{a}}-u_{\mathrm{w}}\right)-\left(u_{\mathrm{a}}-u_{\mathrm{w}}\right)_{\mathrm{b}}\right]}, \quad \text { when }\left(u_{\mathrm{a}}-u_{\mathrm{w}}\right)>\left(u_{\mathrm{a}}-u_{\mathrm{w}}\right)_{\mathrm{b}},
\end{aligned}
$$


where $m$ and $n$ are the two parameters representing the intercept and slope when equation ( $3 b$ ) is transformed into a linear equation, respectively, and $n$ is further fitted as $(1 / n)=$ $-2.4598+1.0225 \varphi$ ' $[37,40]$.

The unified strength theory was proposed by $\mathrm{Yu}$ [30] to account for the intermediate principal stress effect. Shear strength of saturated soils under plane strain conditions from the unified strength theory is derived as

$$
\begin{aligned}
\tau_{\mathrm{f}}=c_{\mathrm{t}}^{\prime}+\sigma \tan \varphi_{\mathrm{t}}^{\prime}, \sin \varphi_{\mathrm{t}}^{\prime} & =\frac{2(1+b) \sin \varphi \prime}{2+b(1+\sin \varphi \prime)}, c_{\mathrm{t}}^{\prime} \\
& =\frac{2(1+b) c \prime \cos \varphi \prime}{2+b\left(1+\sin \varphi^{\prime}\right)} \frac{1}{\cos \varphi_{\mathrm{t}}^{\prime \prime}}
\end{aligned}
$$

where $c_{\mathrm{t}}^{\prime}$ is the unified effective cohesion, $\varphi_{\mathrm{t}}^{\prime}$ is the unified effective internal friction angle, and $b$ is the unified strength theory parameter, $0 \leq b \leq 1$.

The value of parameter $b$ is expressed as

$$
b=\frac{\left(\sigma_{\mathrm{c}}+\sigma_{\mathrm{t}}\right) \tau_{\mathrm{o}}-\sigma_{\mathrm{t}} \sigma_{\mathrm{c}}}{\left(\sigma_{\mathrm{t}}-\tau_{\mathrm{o}}\right) \sigma_{\mathrm{c}}}
$$

where $\sigma_{\mathrm{c}}$ is the uniaxial compressive strength, $\sigma_{\mathrm{t}}$ is the uniaxial tensile strength, and $\tau_{\mathrm{o}}$ is the pure shear strength.

The parameter $b$ not only describes the effect of intermediate principal stress, but also represents a choice of different failure criteria. Limit loci of the unified strength theory on a deviatoric plane are shown in Figure 1. Different failure criteria are achieved with the variation of parameter $b$. Moreover, the Mohr-Coulomb criterion is the lower bound with $b=0$, while the twin-shear stress criterion is the upper bound with $b=1$ [30].

Therefore, when $b=0$, equation (4) becomes to equation (1) with the Mohr-Coulomb criterion; when $b=1$, equation (4) reduces to that with the twin-shear stress criterion; when $0<b<1$, a series of new shear strength equations are introduced from equation (4). The intermediate principal stress effect is clearly presented by the parameter $b$ varying from 0 to 1 . In addition, a specific value of parameter $b$ is in correspondence with the type of soils, and its calibration needs true triaxial test results. The parameter $b$ is not simply a fitting parameter that can be obtained by three approaches: (1) the value of $b$ is calculated through equation (5) when an unsaturated soil element fails in a pure shear stress state; (2) the value of $b$ is found by comparing limit loci of the unified strength theory with true triaxial test results; (3) the value of $b$ is obtained by a comparison of estimated results with measured ones of practical engineering problems such as the slope stability and the bearing capacity of shallow foundations.

Zhang et al. [36,37] have taken comprehensive effects of matric suction and intermediate principal stress into account and then presented a unified equation for the shear strength of unsaturated soils under plane strain conditions by using the analogy method. The unified shear strength equation of unsaturated soils under a plane strain condition is formulated as

$\tau_{\mathrm{f}}=c_{\mathrm{t}}^{\prime}+\left(\sigma-u_{\mathrm{a}}\right) \tan \varphi_{\mathrm{t}}^{\prime}+\left(u_{\mathrm{a}}-u_{\mathrm{w}}\right) \tan \varphi_{\mathrm{t}}^{\mathrm{b}}=c_{\mathrm{tt}}+\left(\sigma-u_{\mathrm{a}}\right) \tan \varphi_{\mathrm{t}}^{\prime}, \sin \varphi_{\mathrm{t}}^{\mathrm{b}}=\frac{2(1+b) \sin \varphi^{\mathrm{b}}}{2+b\left(1+\sin \varphi^{\mathrm{b}}\right)}, \quad c_{\mathrm{tt}}=c_{\mathrm{t}}^{\prime}+\left(u_{\mathrm{a}}-u_{\mathrm{w}}\right) \tan \varphi_{\mathrm{t}}^{\mathrm{b}}$,

where $\varphi_{\mathrm{t}}^{\mathrm{b}}$ is the unified friction angle related to matric suction and $c_{\mathrm{tt}}$ is the unified total cohesion.

When $\left(u_{\mathrm{a}}-u_{\mathrm{w}}\right)=0$, equation (6) becomes to be equation (4) for saturated soils with the unified strength theory; when $b=0$ or 1, equation (6) degenerates into equation (2) for unsaturated soils with the Mohr-Coulomb criterion and the twinshear stress criterion, respectively; when $0<b<1$, equation (6) corresponds to a series of new shear strength equations for unsaturated soils.

2.2. Profiles of Matric Suction. Two profiles of matric suction are allowed for $[9,10,16,40]$ : the uniform suction $\left(u_{\mathrm{a}}-u_{\mathrm{w}}\right)$ in Figure 2(a) is a constant with depth, and the linear suction in Figure 2(b) decreases linearly with depth from the surface suction $\left(u_{\mathrm{a}}-u_{\mathrm{w}}\right)_{0}$ at the ground surface and becomes zero at the water table $D_{\mathrm{w}}$. When the water table $D_{\mathrm{w}} \longrightarrow \infty$, the change of matric suction along depth can be neglected and linear suction becomes uniform suction.

2.3. Ultimate Bearing Capacity of Strip Foundations with Terzaghi's Theory. Terzaghi's ultimate bearing capacity of strip foundations in saturated soils is provided by effective cohesion, surcharge, and soil weight. The ultimate bearing capacity $q_{\mathrm{u}}$ is analyzed by limit equilibrium method of a rigidplasticity body with the Mohr-Coulomb criterion. Figure 3 shows Terzaghi's failure mode of a shallow strip foundation [1], where $B$ is the width of strip foundations and $D$ is the buried depth. The water table $D_{\mathrm{w}}$ is assumed to be located below the sliding surface of strip foundations.

Conventional Terzaghi's ultimate bearing capacity of a strip foundation in saturated soils with equation (1) is written as

$$
q_{\mathrm{u}}=\frac{1}{2} \gamma B N_{\gamma}+q N_{q}+c N_{c}
$$

where $\gamma$ is the unit weight of foundation soils, $q$ is the surcharge equal to soil weights above foundation base, and $q$ is the $\gamma D ; N_{c}, N_{q}$, and $N_{\gamma}$ are the bearing capacity factors of effective cohesion, surcharge, and soil weight using the Mohr-Coulomb criterion, respectively, which are expressed as 


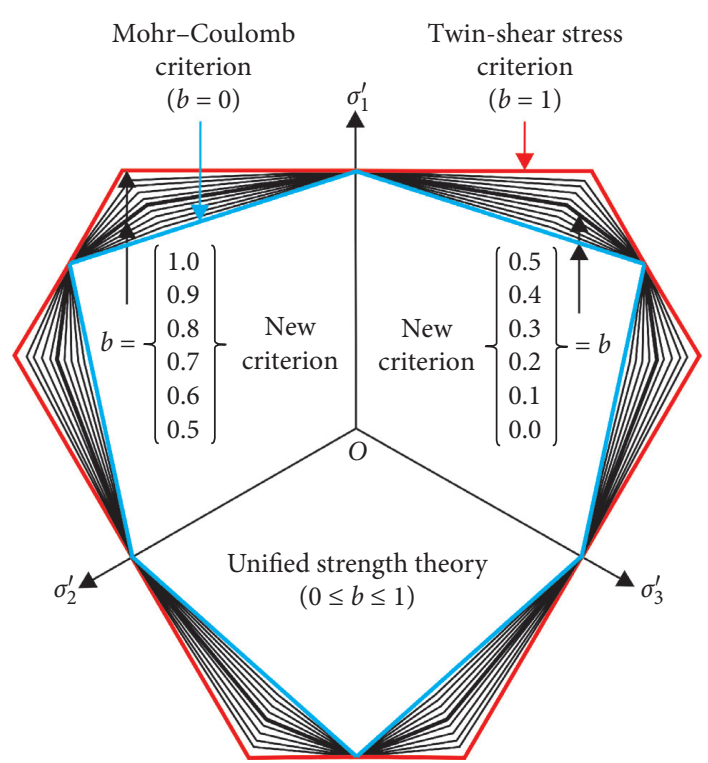

FIgURE 1: Limit loci of the unified strength theory on a deviatoric plane [30].

$$
\begin{aligned}
& N_{c}=\tan \psi+\frac{\cos \left(\psi-\varphi^{\prime}\right)}{\cos \psi \sin \varphi^{\prime}} \times\left\{\left(1+\sin \varphi^{\prime}\right) \exp \left[\left(\frac{3 \pi}{2}+\varphi^{\prime}-2 \psi\right) \tan \varphi^{\prime}\right]-1\right\} \\
& N_{q}=\frac{\cos \left(\psi-\varphi^{\prime}\right)}{\cos \psi} \times \exp \left[\left(\frac{3 \pi}{2}+\varphi^{\prime}-2 \psi\right) \tan \varphi^{\prime}\right] \tan \left(\frac{\pi}{4}+\frac{\varphi^{\prime}}{2}\right) \\
& N_{\gamma}=1.8\left(N_{q}-1\right) \tan \varphi^{\prime}
\end{aligned}
$$

where $\psi$ is the angle between the plane EG and foundation base $\mathrm{EF}$ and $\psi=\varphi^{\prime}$ for a completely rough foundation base, or $\psi=45^{\circ}+\varphi^{\prime} / 2$ for a completely smooth one. Moreover, equation $(8 \mathrm{c})$ is a semiempirical equation proposed by Terzaghi [1].

Oloo et al. [18] established a formulation of ultimate bearing capacity for strip foundations in unsaturated soils with equation (2), and the formulation is given as

$$
q_{\mathrm{u}}=\frac{1}{2} \gamma B N_{\gamma}+q N_{q}+\left[c \prime+\left(u_{\mathrm{a}}-u_{\mathrm{w}}\right) \tan \varphi^{\mathrm{b}}\right] N_{c} \text {. }
$$

The contribution of matric suction to bearing capacities of unsaturated soils is represented by $\left(u_{\mathrm{a}}-u_{\mathrm{w}}\right) \tan \varphi^{\mathrm{b}} \times N_{c}$ in equation (9). When $\left(u_{\mathrm{a}}-u_{\mathrm{w}}\right)=0$, equation (9) becomes to be equation (7) for saturated soils.

Fan et al. [44] applied the unified strength theory to account for the effect of intermediate principal stress and obtained a unified expression of ultimate bearing capacity for strip foundations in saturated soils with equation (4). This unified expression is written as

$$
q_{\mathrm{u}}=\frac{1}{2} \gamma B N_{\gamma \mathrm{t}}+q N_{q \mathrm{t}}+c_{\mathrm{t}}^{\prime} N_{c \mathrm{t}}
$$

where $N_{c t}, N_{q \mathrm{t}}$, and $N_{\gamma \mathrm{t}}$ are the bearing capacity factors based on the unified strength theory, which are expressed as

$$
\begin{aligned}
& N_{c \mathrm{t}}=\tan \psi+\frac{\cos \left(\psi-\varphi_{\mathrm{t}}^{\prime}\right)}{\cos \psi \sin \varphi_{\mathrm{t}}^{\prime}} \times\left\{\left(1+\sin \varphi_{\mathrm{t}}^{\prime}\right) \exp \left[\left(\frac{3 \pi}{2}+\varphi_{\mathrm{t}}^{\prime}-2 \psi\right) \tan \varphi_{\mathrm{t}}^{\prime}\right]-1\right\} \\
& N_{q \mathrm{t}}=\frac{\cos \left(\psi-\varphi_{\mathrm{t}}^{\prime}\right)}{\cos \psi} \times \exp \left[\left(\frac{3 \pi}{2}+\varphi_{\mathrm{t}}^{\prime}-2 \psi\right) \tan \varphi_{\mathrm{t}}^{\prime}\right] \tan \left(\frac{\pi}{4}+\frac{\varphi_{\mathrm{t}}^{\prime}}{2}\right) \\
& N_{\gamma \mathrm{t}}=1.8\left(N_{q \mathrm{t}}-1\right) \tan \varphi_{\mathrm{t}}^{\prime}
\end{aligned}
$$

where $\psi=\varphi_{\mathrm{t}}^{\prime}$ for a completely rough foundation base or $\psi=45^{\circ}+\varphi_{\mathrm{t}}^{\prime} / 2$ for a completely smooth one.
Equation (10) only includes the effect of intermediate principal stress not considering matric suction. When $b=0$, 


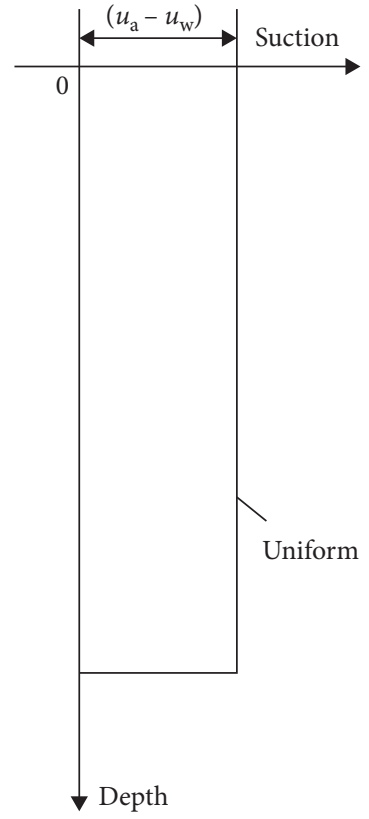

(a)

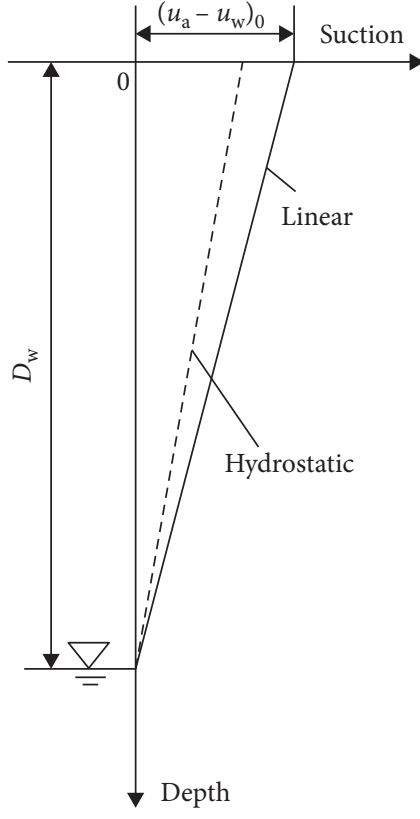

(b)

FIgure 2: Two profiles of matric suction. (a) Uniform suction. (b) Linear suction.

equation (10) reduces to equation (7) with the Mohr-Coulomb criterion not accounting for the intermediate principal stress effect.

Equations (9) and (10) merely reflect the effects of matric suction and intermediate principal stress, respectively. The unified shear strength equation for unsaturated soils under plane strain conditions as expressed in equation (6) is capable of describing comprehensive effects of matric suction and intermediate principal stress. Hence, equation (6) can be utilized to present a new formulation of ultimate bearing capacity for strip foundations in unsaturated soils with consideration of the intermediate principal stress effect.

\section{Ultimate Bearing Capacity of Strip Foundations in Unsaturated Soils}

The effect of intermediate principal stress and two profiles of matric suction (i.e., uniform and linear suctions) would be taken into account to derive the ultimate bearing capacity of a strip foundation in unsaturated soils.
3.1. Uniform Suction with Depth. The assumption of a uniform suction profile is widely used in geotechnical engineering problems of unsaturated soils $[16,36,37,40]$, such as the Earth pressure on retaining walls, the slope stability, and the bearing capacity of shallow foundations. The uniform suction profile is preferred because theoretical solutions of geotechnical engineering problems in unsaturated soils could be conveniently extended from those of saturated soils. For the case of uniform suction, strip foundations are in a general shear failure model, as shown in Figure 3. The wedge EFG is always in an elastic state, and EG is the inner boundary of a sliding zone with an angle $\psi$ between EG and the horizontal plane.

Unsaturated soils in the sliding zone are in a plastic equilibrium state consisting of radial shear zone (2) and Rankine passive zone. (3) The sliding surface can be described by a log spiral as

$$
r=r_{0} \exp \left(\theta \tan \varphi_{\mathrm{t}}^{\prime}\right)=r_{0} \exp \left\{\frac{\theta\left[2(1+b) \sin \varphi^{\prime}\right]}{\sqrt{\left[2+b\left(1+\sin \varphi^{\prime}\right)\right]^{2}-\left[2(1+b) \sin \varphi^{\prime}\right]^{2}}}\right\}
$$

where $r_{0}$ is the initial radius (i.e., the length of EG or FG) and $\theta$ is the angle between any radius $r$ and the initial radius $r_{0}$, which are shown in Figure 3.

Figure 4 illustrates the force analysis of an elastic wedge EFG, where $Q_{\mathrm{u}}$ is the ultimate load of a strip foundation. Then, vertical force equilibrium of the elastic wedge EFG is written as

$$
Q_{\mathrm{u}}=2 P_{\mathrm{p}} \cos \left(\psi-\varphi_{\mathrm{t}}^{\prime}\right)+c_{\mathrm{tt}} B \tan \psi-\frac{1}{4} \gamma B^{2} \tan \psi
$$

where $P_{\mathrm{p}}$ is the total passive Earth pressure acting on the boundary surface EG (or FG).

The total passive Earth pressure $P_{\mathrm{p}}$ given in equation (14) resulted from the unified total cohesion $c_{\mathrm{tt}}$, the surcharge $q$, and the soil weight $\gamma[1,44]$, respectively. For a completely 


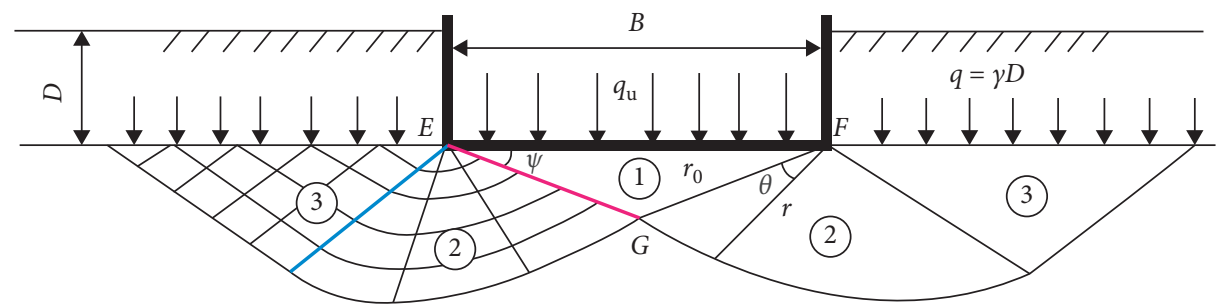

Figure 3: Failure mode of strip foundations based on Terzaghi's theory.

rough base, Terzaghi regarded the elastic wedge boundary EG as a retaining wall surface on the basis of the Earth pressure theory to determine the passive Earth pressure $P_{\mathrm{p}}$ :

$$
P_{\mathrm{p}} \cos \left(\psi-\varphi_{\mathrm{t}}^{\prime}\right)=P_{\mathrm{p} y}=P_{\mathrm{p} c}+P_{\mathrm{p} q}+P_{\mathrm{p} \gamma},
$$

where $P_{\mathrm{p} y}$ is the vertical component of $P_{\mathrm{p}}$.

$P_{\mathrm{p} y}$ is calculated in three steps as follows:

(1) When $q=\gamma=0$, the passive Earth pressure $P_{\mathrm{p} c}$ only caused by the cohesion $c_{\mathrm{tt}}$ is obtained as

$$
\begin{aligned}
& P_{\mathrm{p} c}=\frac{1}{2} c_{\mathrm{tt}} B \tan \psi \times k_{\mathrm{p} c}, \\
& k_{\mathrm{pc}}=\frac{\cos \left(\psi-\varphi_{\mathrm{t}}^{\prime}\right)}{\sin \psi \sin \varphi_{\mathrm{t}}^{\prime}}\left\{\left(1+\sin \varphi_{\mathrm{t}}^{\prime}\right) \exp \left[\left(\frac{3 \pi}{2}+\varphi_{\mathrm{t}}^{\prime}-2 \psi\right) \tan \varphi_{\mathrm{t}}^{\prime}\right]-1\right\},
\end{aligned}
$$

where $k_{\mathrm{p} c}$ is the coefficient of passive Earth pressure for cohesion.

(2) When $c_{\mathrm{tt}}=\gamma=0$, the passive Earth pressure $P_{\mathrm{p} q}$ only caused by the surcharge $q$ is calculated as

$$
\begin{aligned}
& P_{\mathrm{p} q}=\frac{1}{2} q B \tan \psi \times k_{\mathrm{p} q} \\
& k_{\mathrm{p} q}=\frac{\cos \left(\psi-\varphi_{\mathrm{t}}^{\prime}\right)}{\sin \psi} \tan \left(\frac{\pi}{4}+\frac{\varphi_{\mathrm{t}}^{\prime}}{2}\right) \exp \left[\left(\frac{3 \pi}{2}+\varphi_{\mathrm{t}}^{\prime}-2 \psi\right) \tan \varphi_{\mathrm{t}}^{\prime}\right],
\end{aligned}
$$

where $k_{\mathrm{p} q}$ is the coefficient of passive Earth pressure for surcharge.

(3) When $c_{\mathrm{tt}}=q=0$, the passive Earth pressure $P_{\mathrm{p} \gamma}$ only caused by the soil weight $\gamma$ is written as

$P_{\mathrm{p} \gamma}=\frac{1}{2} \gamma\left(\frac{1}{2} B \tan \psi\right)^{2} k_{\mathrm{p} \gamma}=\frac{1}{8} \gamma B^{2} \tan ^{2} \psi \times k_{\mathrm{p} \gamma}$,

where $k_{\mathrm{p} \gamma}$ is the coefficient of passive Earth pressure for soil weight and $k_{\mathrm{p} \gamma}$ needs to be determined by a trial method.

More detailed derivations of the above three passive Earth pressure components can be found in Terzaghi [1] and Fan et al. [44]. Then, the vertical component $P_{\mathrm{p} y}$ of total passive Earth pressure is brought by superimposing equations (15)-(17) as

$$
P_{\mathrm{p} y}=P_{\mathrm{p} c}+P_{\mathrm{p} q}+P_{\mathrm{p} \gamma}=\frac{B \tan \psi}{2}\left(c_{\mathrm{tt}} k_{\mathrm{p} c}+q k_{\mathrm{p} q}+\frac{1}{4} \gamma B \tan \psi k_{\mathrm{p} \gamma}\right) \text {. }
$$

Substituting equations (14) and (18) into (13), the ultimate bearing capacity $q_{\mathrm{u}}$ of strip foundations in unsaturated soils for uniform suction can be rearranged as

$$
q_{\mathrm{u}}=\frac{Q_{\mathrm{u}}}{B}=\frac{1}{2} \gamma B N_{\gamma \mathrm{t}}+q N_{q \mathrm{t}}+c_{\mathrm{tt}} N_{c \mathrm{t}}=\frac{1}{2} \gamma B N_{\gamma \mathrm{t}}+q N_{q \mathrm{t}}+\left[c_{\mathrm{t}}^{\prime}+\left(u_{\mathrm{a}}-u_{\mathrm{w}}\right) \tan \varphi_{\mathrm{t}}^{\mathrm{b}}\right] N_{c t} .
$$

Through some mathematical transformations, $N_{c t}, N_{q \mathrm{t}}$, and $N_{\gamma \mathrm{t}}$ are found to be the same as equations (11a)-(11c).

Equation (19) can represent comprehensive effects of intermediate principal stress $(0 \leq b \leq 1)$ and uniform suction $\left(u_{\mathrm{a}}-u_{\mathrm{w}}\right)$. The unified strength theory parameter $b$ depicts the effect of intermediate principal stress as well as the selection of different failure criteria. When $b=0$, equation (19) degenerates into equation (9) for unsaturated soils with the Mohr-Coulomb criterion; when $b=1$, equation (19) becomes the ultimate bearing capacity for unsaturated soils with the two-shear stress criterion; when $0<b<1$, equation
(19) generates a series of new ultimate bearing capacity equations for strip foundations in unsaturated soils. Matric suction $\left(u_{\mathrm{a}}-u_{\mathrm{w}}\right)>0$ corresponds to an unsaturated state of foundation soils. When $\left(u_{\mathrm{a}}-u_{\mathrm{w}}\right)=0$, equation (19) reverts to equation (10) for saturated soils with the unified strength theory. When $b=0$ and $\left(u_{\mathrm{a}}-u_{\mathrm{w}}\right)=0$, equation (19) reduces to equation (7) for saturated soils with the Mohr-Coulomb criterion.

3.2. Linear Suction with Depth. For the case of linear suction, matric suction decreases linearly with depth and 


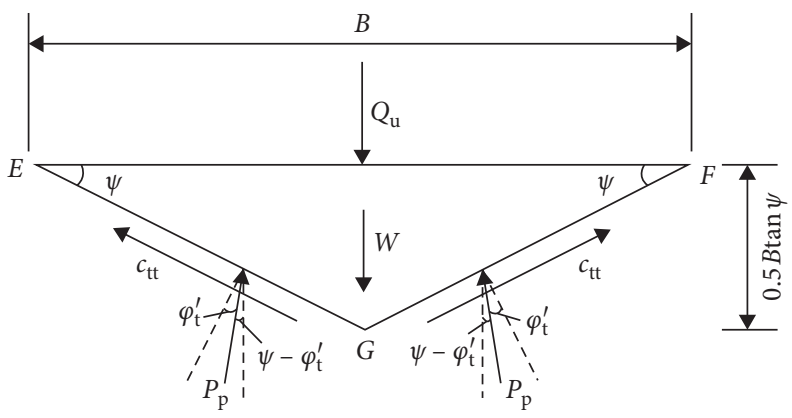

Figure 4: Force analysis of an elastic wedge EFG.

becomes zero at the water table $D_{\mathrm{w}}$. As illustrated in Figure 5, Oh et al. [21, 22, 45] defined the average matric suction $\left(u_{\mathrm{a}}-u_{\mathrm{w}}\right)_{\mathrm{m}}$ at the centroid of zone (1) correspondingly to the stress bulb within a depth of $1.5 \mathrm{~B}$ beneath foundation base as a representative matric suction value. The value of $\left(u_{\mathrm{a}}-u_{\mathrm{w}}\right)_{\mathrm{m}}$ can be adopted to calculate the contribution of matric suction with a linear profile to the ultimate bearing capacity of strip foundations. The zone (1) in Figure 5(a) is a trapezoid with a height of $1.5 B$, a top side length of $\left(1-D / D_{\mathrm{w}}\right)\left(u_{\mathrm{a}}-u_{\mathrm{w}}\right)_{0}$, and a bottom side length of $\left(1-(D+1.5 B) / D_{\mathrm{w}}\right)\left(u_{\mathrm{a}}-u_{\mathrm{w}}\right)_{0}$. The location of the centroid for zone (1) is assumed at a distance $h$ from the bottom side. According to the theorem of area moment, $h$ is obtained as

$$
h=\frac{3 B\left(D_{\mathrm{w}}-D-0.5 B\right)}{4\left(D_{\mathrm{w}}-D-0.75 B\right)} .
$$

Then, $\left(u_{\mathrm{a}}-u_{\mathrm{w}}\right)_{\mathrm{m}}$ is derived as

$$
\left(u_{\mathrm{a}}-u_{\mathrm{w}}\right)_{\mathrm{m}}=\left(u_{\mathrm{a}}-u_{\mathrm{w}}\right)_{0}\left(1-\frac{D+1.5 B-h}{D_{\mathrm{w}}}\right) .
$$

By implementing similar derivations of uniform suction with depth in Section 3.1, the ultimate bearing capacity of strip foundations in unsaturated soils for linear suction is written as

$q_{\mathrm{u}}=\frac{1}{2} \gamma B N_{\gamma \mathrm{t}}+q N_{q \mathrm{t}}+\left[c_{\mathrm{t}}^{\prime}+\left(u_{\mathrm{a}}-u_{\mathrm{w}}\right)_{0}\left(1-\frac{D+1.5 B-h}{D_{\mathrm{w}}}\right) \tan \varphi_{\mathrm{t}}^{\mathrm{b}}\right] N_{c t}$.

It is seen from equation (22) that the effect of linear suction is accounted for by the surface suction $\left(u_{\mathrm{a}}-u_{\mathrm{w}}\right)_{0}$ and the water table $D_{\mathrm{w}}$. When the water table $D_{\mathrm{w}} \longrightarrow \infty$, the change of matric suction along depth can be neglected and linear suction becomes uniform suction; then, equation (22) reduces to equation (19) for uniform suction (i.e., equation (19) is a special case of equation (22) for $D_{\mathrm{w}} \longrightarrow \infty$ ).

The matric suction of unsaturated soils is more of a nonlinear profile with depth that mainly depends on the soil characteristics (such as the soil type, soil saturation level, and saturated hydraulic conductivity) and different environmental conditions (surface evaporation and rainfall) or man-made activities. Regarding shallow

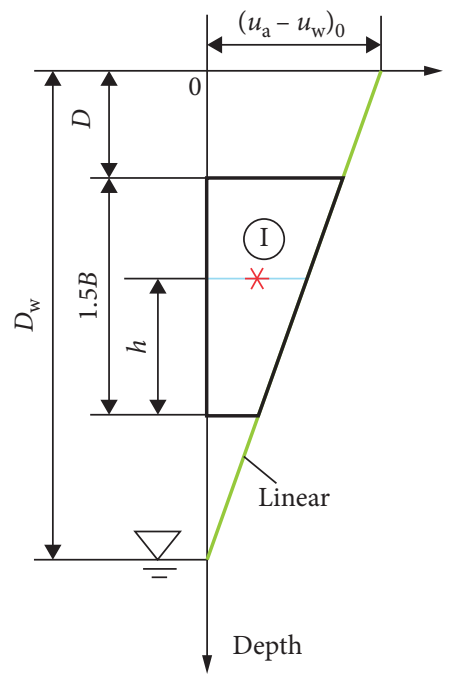

(a)

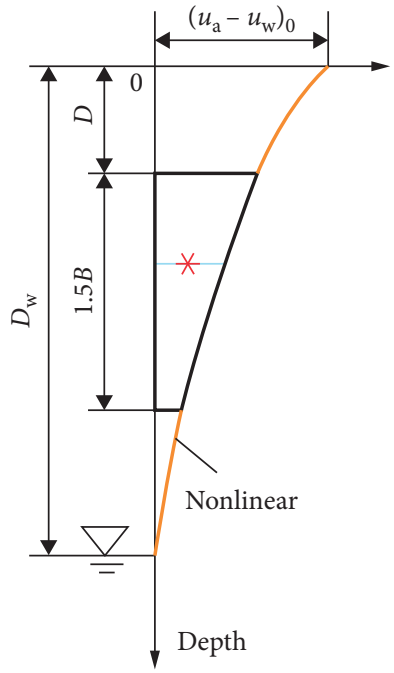

(b)
FIgURE 5: Average matric suction under the nonuniform suction profiles. (a) Linear suction. (b) Nonlinear suction.

foundations of buildings or roads, there are some protective measures existing on the ground surface. The unsaturation profile of near-surface soils is thus in a steady state and is less affected by environmental conditions and man-made activities. In the absence of measured suction data in practice, the assumption of linear suction above the water table can be made under a hydrostatic pressure condition. This is a safe assumption as a conservative ultimate bearing capacity is obtained, and its calculation process is simple and practical.

This study merely addresses two simple suction profiles, i.e., the uniform and linear suction profiles. For a measured suction profile or nonlinear suction profile shown in Figure 5(b), the average matric suction concept can be extended based on similar procedures in this paper, and then the ultimate bearing capacity of strip foundations in unsaturated soils is easily obtained.

\section{Validation of the Proposed Formulation}

The validity of the proposed ultimate bearing capacity formulations as expressed in equations (19) and (22) is 
verified by comprising with the results of Vanapalli and Mohamed [19] and Zhao et al. [20].

4.1. A Comparison with the Result of Vanapalli and Mohamed [19]. Rectangular foundation model tests for estimating the ultimate bearing capacity of unsaturated coarse-grained soils were carried out by Vanapalli and Mohamed [19]. The size of a model tank is length $\times$ width $\times$ height $=900 \mathrm{~mm} \times$ $900 \mathrm{~mm} \times 750 \mathrm{~mm}$, and the size of a foundation is $B \times L=100 \mathrm{~mm} \times 100 \mathrm{~mm}$; soil parameters are $\gamma=16.02 \mathrm{kN} /$ $\mathrm{m}^{3}, c^{\prime}=0.6 \mathrm{kPa}$, and $\varphi^{\prime}=35.3^{\circ}$. The rectangular foundation was placed on the ground surface with $D=0$. The air-entry value $\left(u_{\mathrm{a}}-u_{\mathrm{w}}\right)_{\mathrm{b}}$ equal to $3 \mathrm{kPa}$ was obtained by the fitted soilwater characteristic curve (SWCC). Vanapalli and Mohamed [19] performed four model tests along with the average matric suction $\left(u_{\mathrm{a}}-u_{\mathrm{w}}\right)_{\mathrm{m}}$ of $0,2,4$, and $6 \mathrm{kPa}$, and the corresponding bearing capacity was $121,570,715$, and $840 \mathrm{kPa}$, respectively. An equation was also presented for estimating the ultimate bearing capacity of rectangular foundations in unsaturated soils by incorporating the degree of saturation and the SWCC. Figure 6 shows the comparison of this study with the result of Vanapalli and Mohamed [19]. Additionally, the angle $\varphi^{\mathrm{b}}$ is determined by Method II with $m=0.5 \mathrm{kPa}$ and $n=0.0297$. The ultimate bearing capacity formulation of this study needs to be modified for a rectangular foundation with shape factors as

$$
q_{\mathrm{u}}=\frac{1}{2} \gamma B N_{\gamma \mathrm{t}} \xi_{\gamma}+q N_{q \mathrm{t}} \xi_{q}+\left[c_{\mathrm{t}}^{\prime}+\left(u_{\mathrm{a}}-u_{\mathrm{w}}\right)_{\mathrm{m}} \tan \varphi_{\mathrm{t}}^{\mathrm{b}}\right] N_{c \mathrm{t}} \xi_{c}
$$

$$
\begin{aligned}
\xi_{\gamma}=1-0.4 \frac{B}{L} \geq 0.6, & \quad \xi_{c}=1+\frac{B}{L} \frac{N_{q \mathrm{t}}}{N_{c t}},
\end{aligned}
$$

where $\xi_{\gamma}, \xi_{q}$, and $\xi_{c}$ are Vesic's shape factors of soil weight, surcharge, and cohesion [3], respectively.

As can be seen from Figure 6, matric suction considerably enhances the ultimate bearing capacity of shallow foundations. When $\left(u_{\mathrm{a}}-u_{\mathrm{w}}\right)_{\mathrm{m}}$ is increased from 0 to $6 \mathrm{kPa}$, $q_{\mathrm{u}}$ of model tests is increased by 5.94 times, so the contribution of matric suction to the ultimate bearing capacity of unsaturated soils is very remarkable. When $b=0.75$, predictions of this study from equation (23) are in good agreement with model test results of Vanapalli and Mohamed [19]. Accordingly, the validity of equation (23) is well demonstrated. On the other hand, Figure 6 suggests that the strength of coarse-grained soils used in this model test should be described by equation (6) with $b=0.75$.

When $b=0$, the prediction of equation (23) is distinctly less than the result of this model test. It means that the Mohr-Coulomb criterion (i.e., $b=0$ ) underestimates actual bearing capacities of unsaturated soils due to neglecting the intermediate principal stress effect. Nevertheless, when $b=1$, the prediction of equation (23) is higher than model test results and exaggerates the improving effect of intermediate principal stress.
In addition, the result of this study with $b=0.75$ is close to the estimation of Vanapalli and Mohamed [19] for a suction range from 0 to $6 \mathrm{kPa}$. However, the estimated ultimate bearing capacity of Vanapalli and Mohamed [19] shows a reduction after matric suction reaches $6 \mathrm{kPa}$. It is because that the degree of saturation in the equation of Vanapalli and Mohamed [19] has a more reducing effect than the strengthening effect of increasing matric suction on the ultimate bearing capacity. In this study, the angle $\varphi^{\mathrm{b}}$ of Method II decreases nonlinearly with increasing matric suction, and the decrease of $\varphi^{\mathrm{b}}$ would reduce the ultimate bearing capacity. There are three cases of the relationship between a strengthening effect of increasing matric suction and a reducing effect of decreasing the angle $\varphi^{\mathrm{b}}$ on the ultimate bearing capacity, and detailed analyses are discussed in Section 5.3. For the specific experimental condition of Vanapalli and Mohamed [19], the reducing effect of $\varphi^{\mathrm{b}}$ is less than the strengthening effect of increasing matric suction, and the reduction in ultimate bearing capacity is not captured in this study while the increasing rate is decreased. Furthermore, the reduction in ultimate bearing capacity of Vanapalli and Mohamed [19] is only predicted not measured. Oh and Vanapalli [21] also revealed the decline in the estimated ultimate bearing capacity of shallow foundations, while there is no decrease in model test results.

4.2. A Comparison with the Result of Zhao et al. [20]. Based on the Mohr-Coulomb criterion, Zhao et al. [20] derived upper-bound solutions of the ultimate bearing capacity for strip foundations in unsaturated soils with uniform and linear suction profiles. Figure 7 shows the comparison between the results of Zhao et al. [20] and this study with equations (19) and (22) for $B=0.5 \mathrm{~m}, D=0.5 \mathrm{~m}$, $D_{\mathrm{w}}=4 \mathrm{~m}, \gamma=18.3 \mathrm{kN} / \mathrm{m}^{3}, c^{\prime}=5 \mathrm{kPa}, \varphi^{\prime}=20^{\circ}$, and $\varphi^{\mathrm{b}}=15^{\circ}$. The parameter $b$ takes three values (i.e., $0,0.5$, and 1 ).

It is indicated from Figure 7 that predictions of this study with $b=0$ not incorporating the intermediate principal stress effect are reasonably consistent with the upper-bound results of Zhao et al. [20] using the Mohr-Coulomb criterion. Furthermore, if the effect of intermediate principal stress is taken effectively, i.e., $b=0.5$ and 1 , the prediction of this study is larger than that of the upper-bound method, particularly for the uniform suction profile in Figure $7(\mathrm{a})$.

\section{Parametric Studies}

Influence characteristics of intermediate principal stress, matric suction, strength nonlinearity from nonlinearity in the angle $\varphi^{\mathrm{b}}$, and base roughness on the ultimate bearing capacity of strip foundations in unsaturated soils are investigated herein for input parameters of $B=4 \mathrm{~m}$, $D=3 \mathrm{~m}, \quad D_{\mathrm{w}}=12 \mathrm{~m}, \quad \gamma=19.5 \mathrm{kN} / \mathrm{m}^{3}, \quad c^{\prime}=20 \mathrm{kPa}$, and $\varphi^{\prime}=30^{\circ}$. The angle $\varphi^{\mathrm{b}}$ of Method II is only considered to discuss the effect of strength nonlinearity, while $\varphi^{\mathrm{b}}=20^{\circ}$ of Method I is used for the other three influence factors. In addition, a completely rough foundation base is adopted in Sections 5.1-5.3. 


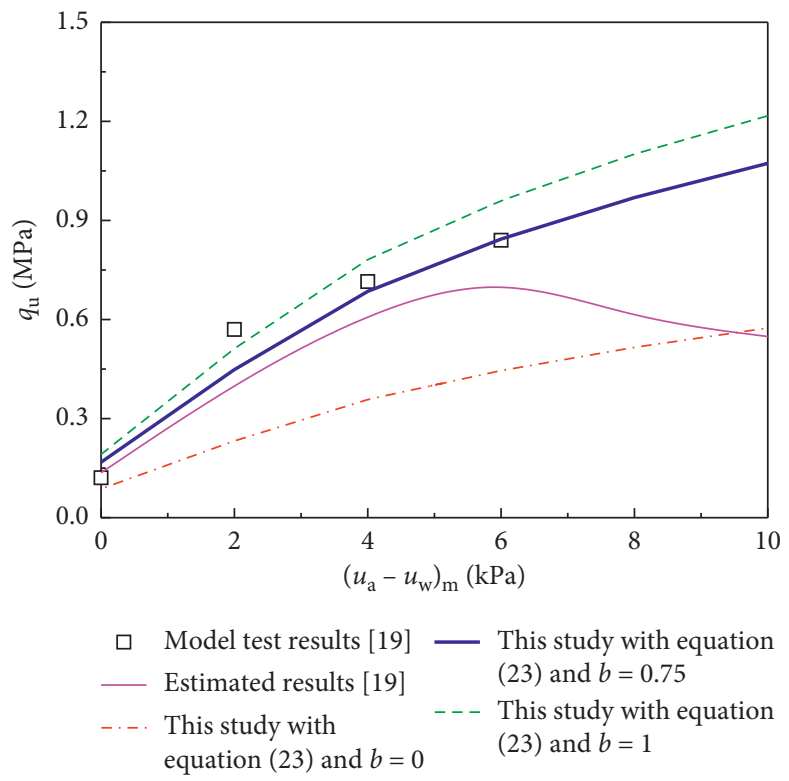

Figure 6: Comparisons with the result of Vanapalli and Mohamed [19].
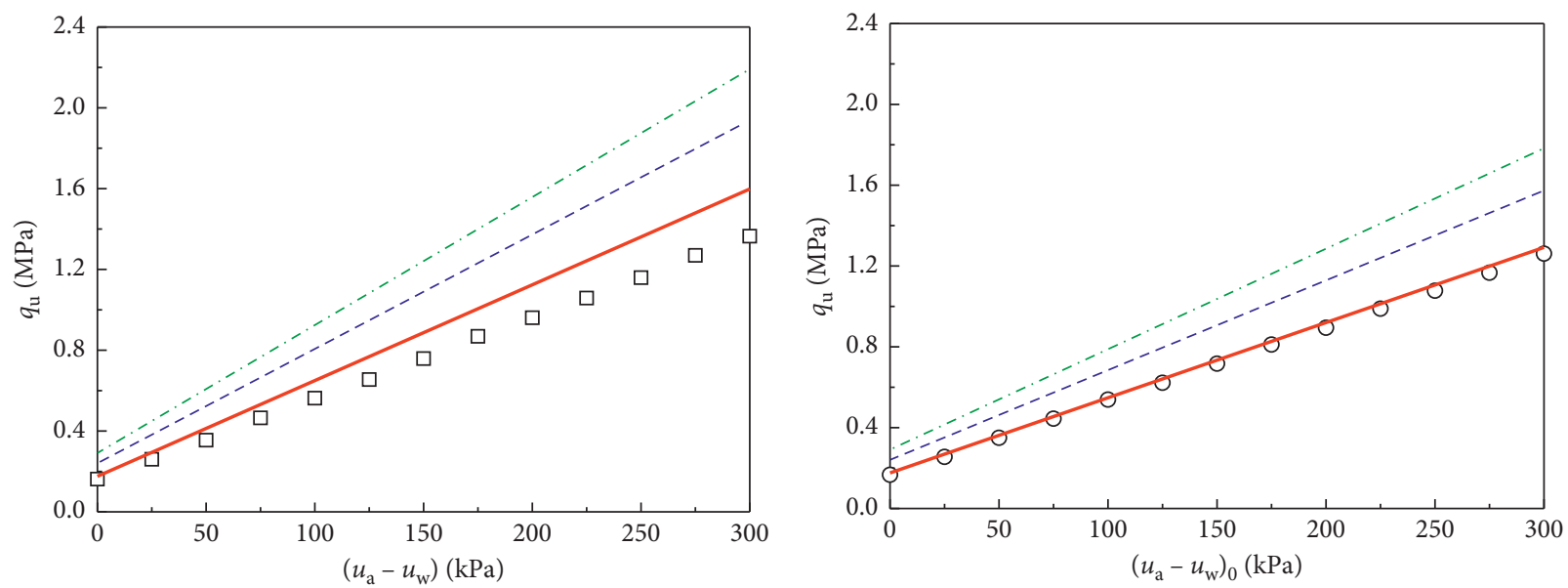

Uniform suction

Zhao et al. [20]

- This study with equation (19) and $b=0$

- - This study with equation (19) and $b=0.5$

-... This study with equation (19) and $b=1$

(a)

Linear suction

o Zhao et al. [20]

- This study with equation (22) and $b=0$

- - - This study with equation (22) and $b=0.5$

-... This study with equation (22) and $b=1$

(b)

FIgURE 7: Comparisons with the result of Zhao et al. [20]. (a) Uniform suction. (b) Linear suction.

5.1. Effect of Intermediate Principal Stress. The effect of intermediate principal stress is described by the parameter $b$ in the unified strength theory, and a larger $b$ value represents a more significant effect of intermediate principal stress. Figure 8 illustrates the variation of ultimate bearing capacity with the change of parameter $b$.

Figure 8 displays that the ultimate bearing capacity $q_{\mathrm{u}}$ has a nearly linear increase with $b$. When $b$ is changed from 0 to $1, q_{\mathrm{u}}$ for the case of uniform suction is increased by $92.7 \%$ for $\left(u_{\mathrm{a}}-u_{\mathrm{w}}\right)=\left(u_{\mathrm{a}}-u_{\mathrm{w}}\right)_{0}=30 \mathrm{kPa}$, which is roughly identical to that of linear suction (increased by $93.4 \%$ ). Therefore, the effect of intermediate principal stress should be taken into account to calculate the ultimate bearing capacity of strip foundations in unsaturated soils, and the result without incorporating the intermediate principal stress effect is conservative. Additionally, $q_{\mathrm{u}}$ in case of linear suction is smaller than that of uniform suction, especially for $\left(u_{\mathrm{a}}-u_{\mathrm{w}}\right)=\left(u_{\mathrm{a}}-u_{\mathrm{w}}\right)_{0}=90 \mathrm{kPa}$. A reasonable profile of matric suction is necessarily estimated in practical engineering. Meanwhile, comparisons of Figures 8(a) and 8(b) indicate 


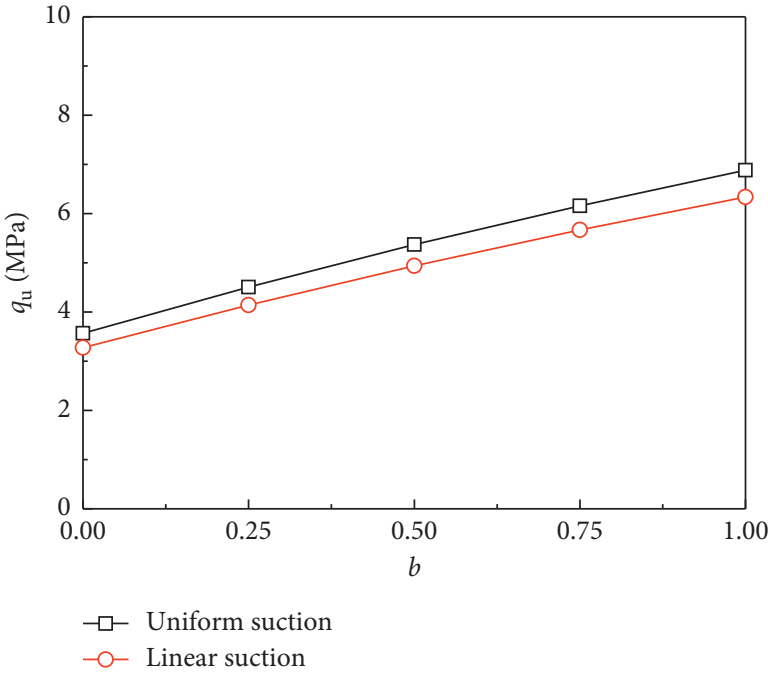

(a)

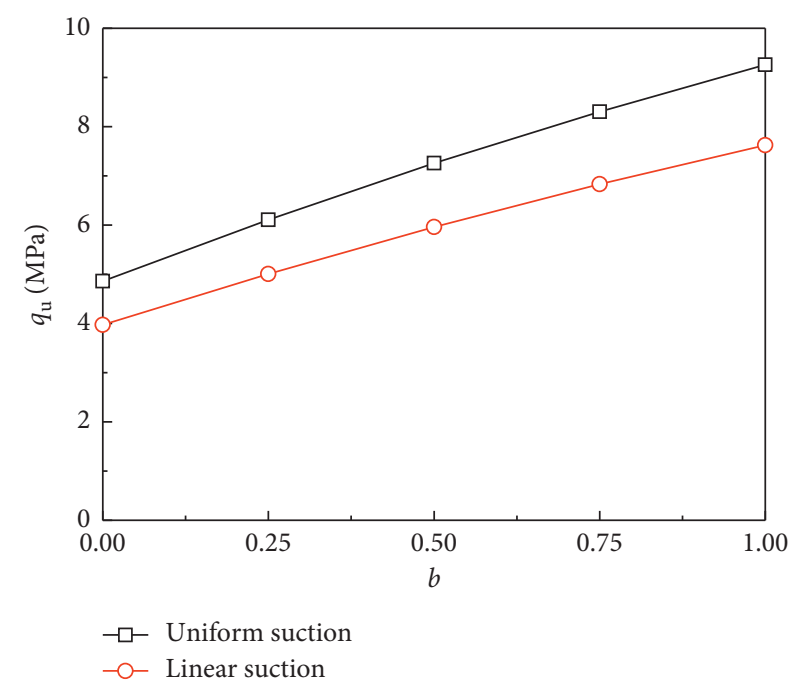

(b)

FIGURE 8: Effect of intermediate principal stress. (a) $\left(u_{\mathrm{a}}-u_{\mathrm{w}}\right)=\left(u_{\mathrm{a}}-u_{\mathrm{w}}\right)_{0}=30 \mathrm{kPa}$. (b) $\left(u_{\mathrm{a}}-u_{\mathrm{w}}\right)=\left(u_{\mathrm{a}}-u_{\mathrm{w}}\right)_{0}=90 \mathrm{kPa}$.

that larger matric suctions will yield a more conspicuous difference in the results between uniform and linear suctions.

5.2. Effect of Matric Suction. Matric suction is a unique property of unsaturated soils, and its influence on the ultimate bearing capacity of unsaturated soils lies in two aspects: suction magnitude and profile pattern. Figure 9 shows the relationship between the ultimate bearing capacity of unsaturated soils and matric suction under uniformly and linearly distributed suctions with $b=0$ and 1 , and matric suction ranges from 0 to $150 \mathrm{kPa}$.

Figure 9 indicates that $q_{\mathrm{u}}$ increases approximately linearly with matric suction. When $b=1$ and matric suction increases from 0 to $150 \mathrm{kPa}, q_{\mathrm{u}}$ in case of uniform suction is increased by $54.6 \%$, which is much larger than that of linear suction (increased by $29.6 \%$ ). Ignoring the change of matric suction along the depth, $q_{\mathrm{u}}$ of uniform suction is rather larger, and then foundation designs based on this assumption may be unsafe. Moreover, the effect of suction profile on the ultimate bearing capacity of strip foundations cannot be neglected. Comparisons between Figures 9(a) and 9(b) suggest that the difference between two suction profiles is larger for $b=1$ than $b=0$. Hence, the influence of matric suction including the suction magnitude and suction prolife is significant, and the profile of matric suction in different situations should be monitored in situ.

5.3. Effect of Strength Nonlinearity. Sections 5.1 and 5.2 have demonstrated that the result of linear suction is similar to that of uniform suction. Accordingly, only uniform suction is considered herein to explore the effect of strength nonlinearity. The air-entry value $\left(u_{\mathrm{a}}-u_{\mathrm{w}}\right)_{\mathrm{b}}$ is assumed to be $90 \mathrm{kPa}, b$ takes 0 and 1 , and matric suction ranges from 0 to $240 \mathrm{kPa}$. Figure 10 presents the effect of strength nonlinearity on the ultimate bearing capacity of a strip foundation in unsaturated soils. The angle $\varphi^{\mathrm{b}}$ of Method I is a small constant with $\varphi^{\mathrm{b}}=20^{\circ}$. For Method II, when $\left(u_{\mathrm{a}}-u_{\mathrm{w}}\right) \leq\left(u_{\mathrm{a}}-u_{\mathrm{w}}\right)_{\mathrm{b}}, \quad \varphi^{\mathrm{b}}=\varphi^{\prime}=30^{\circ} ; \quad$ once $\quad\left(u_{\mathrm{a}}-u_{\mathrm{w}}\right)$ $>\left(u_{\mathrm{a}}-u_{\mathrm{w}}\right)_{\mathrm{b}}, \varphi^{\mathrm{b}}$ is calculated from equation (3b) with $n=0.0354$, and $m$ is taken as 1,5 , and $20 \mathrm{kPa}$, respectively.

It can be seen from Figure 10 that $q_{\mathrm{u}}$ of Method I increases linearly without a turning point. However, the result of Method II is divided into two stages: when $\left(u_{\mathrm{a}}-u_{\mathrm{w}}\right) \leq\left(u_{\mathrm{a}}-u_{\mathrm{w}}\right)_{\mathrm{b}}=90 \mathrm{kPa}, q_{\mathrm{u}}$ increases linearly with $\left(u_{\mathrm{a}}-u_{\mathrm{w}}\right)$; when $\left(u_{\mathrm{a}}-u_{\mathrm{w}}\right)>\left(u_{\mathrm{a}}-u_{\mathrm{w}}\right)_{\mathrm{b}}=90 \mathrm{kPa}, q_{\mathrm{u}}$ is closely related to the parameter $m$. A comparison between the predictions of Method I and Method II implies the result of Method II is larger than that of Method I in the low suction region of $\left(u_{\mathrm{a}}-u_{\mathrm{w}}\right) \leq\left(u_{\mathrm{a}}-u_{\mathrm{w}}\right)_{\mathrm{b}}=90 \mathrm{kPa}$. This is because $\varphi^{\mathrm{b}}$ of Method I is smaller than that of Method II in the low suction region. In the high suction region of $\left(u_{\mathrm{a}}-u_{\mathrm{w}}\right)$ $>\left(u_{\mathrm{a}}-u_{\mathrm{w}}\right)_{\mathrm{b}}=90 \mathrm{kPa}$, relative magnitude of the predictions from Method I and Method II is dependent on the parameter $m$.

The value of $m$ can describe the dual-effect of high suction on the ultimate bearing capacity through the relationship between a strengthening effect of increasing matric suction and a reducing effect of decreasing the angle $\varphi^{\mathrm{b}}$. There are three cases of this dual effect. Case 1: when the reducing effect of $\varphi^{\mathrm{b}}$ is more pronounced than the strengthening effect of matric suction, $q_{\mathrm{u}}$ decreases nonlinearly with matric suction and approaches a constant value, which is in accordance with the result of $m=1 \mathrm{kPa}$. Case 2 : when the reducing effect of $\varphi^{\mathrm{b}}$ is slightly weaker than the strengthening effect of matric suction, $q_{\mathrm{u}}$ increases somewhat with matric suction corresponding to that of $m=5 \mathrm{kPa}$. Case 3: when the reducing effect of $\varphi^{\mathrm{b}}$ is much less than the strengthening effect of matric suction, $q_{\mathrm{u}}$ increases markedly with matric suction, and the result of $m=20 \mathrm{kPa}$ belongs to this case. 


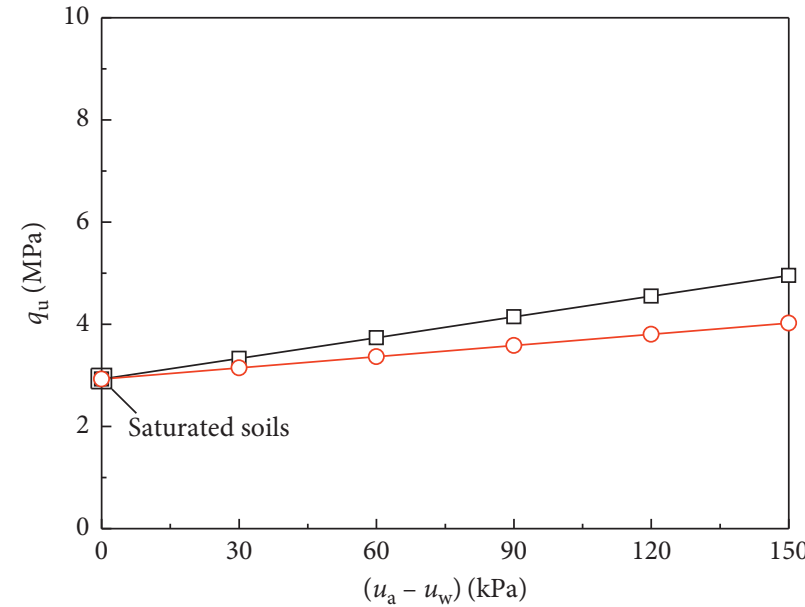

$\square-$ Uniform suction

$-\mathrm{O}$ Linear suction

(a)

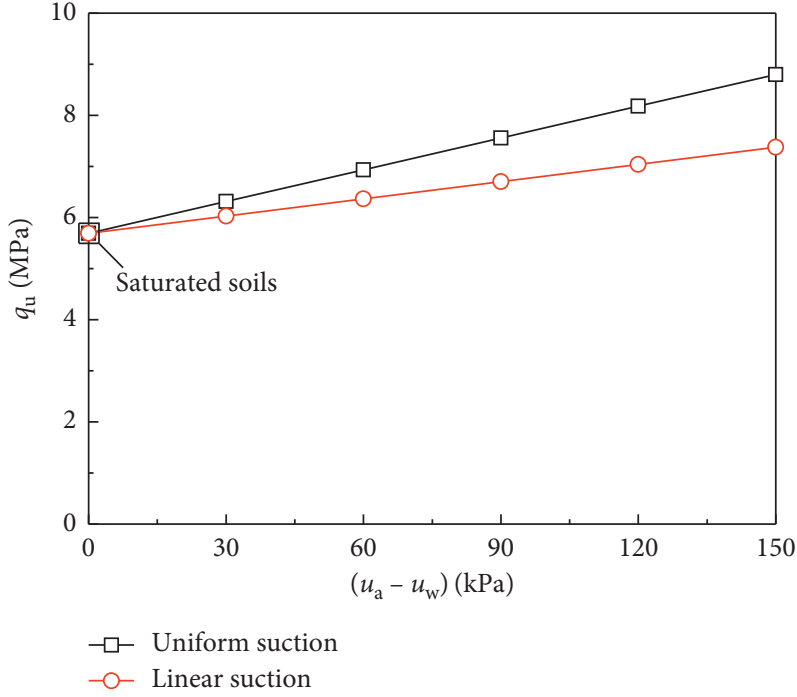

(b)

Figure 9: Effect of matric suction. (a) $b=0$. (b) $b=1$.

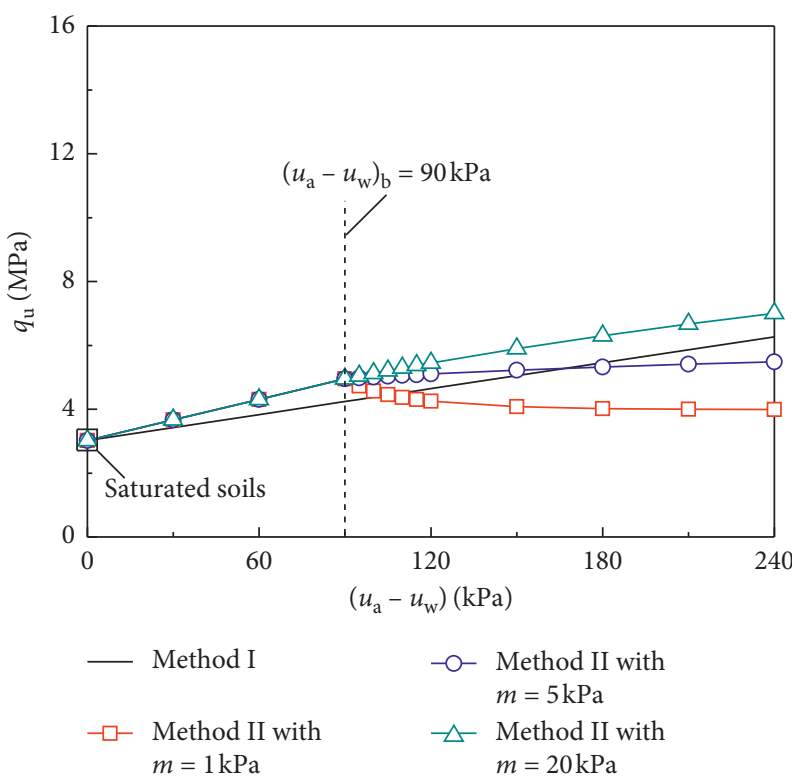

(a)

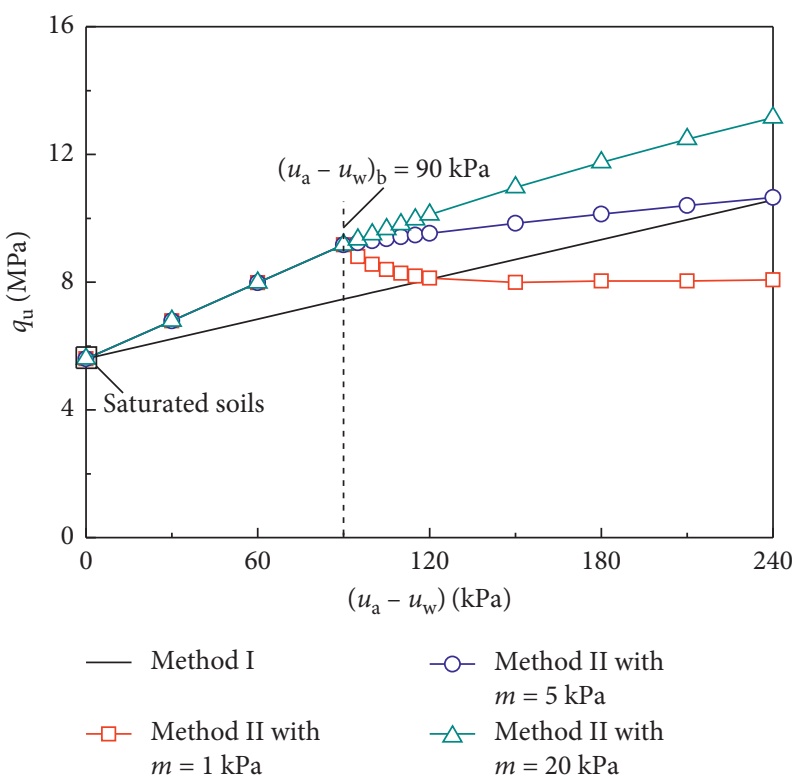

(b)

Figure 10: Effect of strength nonlinearity. (a) $b=0$. (b) $b=1$.

Consequently, high suction has a complex dual effect and $m$ can be referred to as an index to characterize the changing velocity of $\varphi^{\mathrm{b}}$ with matric suction. Variation laws of the ultimate bearing capacity for strip foundations under high suction values are in fact attributed to strength nonlinearity of unsaturated soils in terms of a decreasing angle $\varphi^{\mathrm{b}}$.

5.4. Effect of Base Roughness. The roughness of foundation base affects the ultimate bearing capacity of strip foundations through directly influencing the angle $\psi$ between the elastic wedge (1) and the horizontal plane EF. The ultimate bearing capacity for two limits of base roughness (i.e., a completely rough base and a completely smooth base) under uniform and linear suctions is shown in Figure 11 with $\left(u_{\mathrm{a}}-u_{\mathrm{w}}\right)=\left(u_{\mathrm{a}}-u_{\mathrm{w}}\right)_{0}=90 \mathrm{kPa}$.

From Figure 11, it can be seen that base roughness has a remarkable influence on the ultimate bearing capacity of strip foundations and $q_{\mathrm{u}}$ of a completely rough base is larger than that of a completely smooth base. In the case of uniform suction, $q_{\mathrm{u}}$ of a completely rough base is increased by $82.3 \%$ 


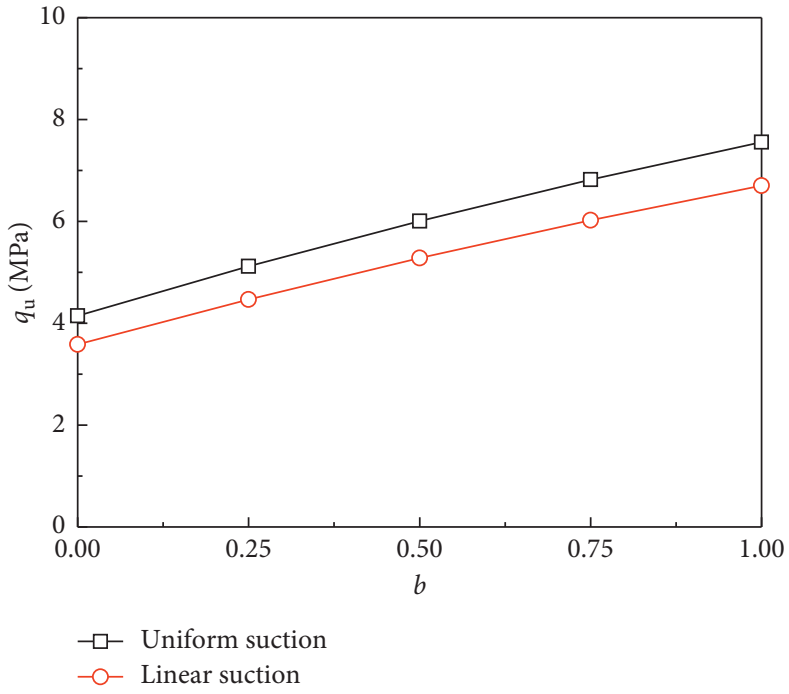

(a)

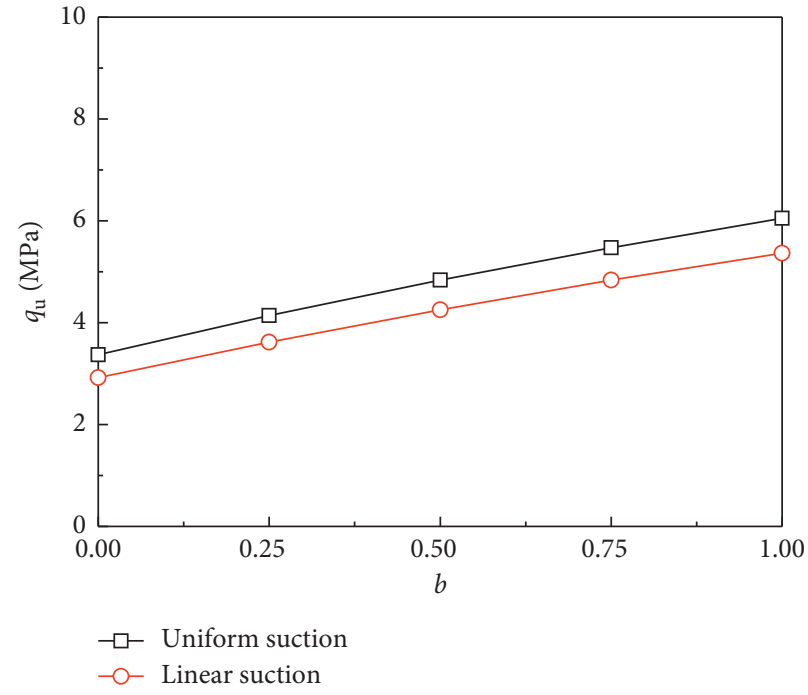

(b)

Figure 11: Effect of base roughness. (a) Completely rough. (b) Completely smooth.

when $b$ varies from 0 to 1 , while that of a completely smooth base is increased by $79.4 \%$. As a result, the intermediate principal stress effect is more pronounced for a completely rough base. Measures should be taken to improve the roughness of foundation base avoiding adverse impacts on foundation safety.

\section{Conclusions}

(1) The ultimate bearing capacity formulation of strip foundations under two suction profiles is presented by incorporating the intermediate principal stress effect. The ultimate bearing capacity equations of strip foundations in saturated soils using the Mohr-Coulomb criterion and using the unified strength theory are both special cases of the proposed formulation. Furthermore, the proposed formulation can degenerate into that of unsaturated soils based on the Mohr-Coulomb criterion. Meanwhile, the validity and wide applicability of this study are confirmed by comprising with model test results and an upper-bound solution available in the literature.

(2) The ultimate bearing capacity of strip foundations is found to be sensitive for improving the effect of intermediate principal stress and increases distinctly with the unified strength theory parameter $b$. The result with $b=0$ not including the intermediate principal stress effect is conservative. Consequently, the effect of intermediate principal stress should be appropriately considered to achieve more potentialities of unsaturated soils and reduce project costs.

(3) Matric suction and its profiles can significantly enhance the ultimate bearing capacity of strip foundations in unsaturated soils. The ultimate bearing capacity increases linearly with matric suction and the effect of uniform suction is more obvious. Field monitoring of matric suction at shallow depths is preferred to accurately model a suction profile. Base roughness is able to markedly affect the ultimate bearing capacity of strip foundations, and reasonable measures are taken to increase the roughness of foundation base.

(4) The effect of strength nonlinearity was investigated by comparing Method I with Method II. Method I with a small and stable value of the angle $\varphi^{\mathrm{b}}$ has simple calculation steps but its results are not precise enough. Method II with a hyperbolic function of the angle $\varphi^{\mathrm{b}}$ is more consistent with practical conditions, but its calculation is more complicated due to the difficulty in obtaining an intercept $m$. The dual effect of high suction on unsaturated soil strength (and thus on the ultimate bearing capacity of strip foundations) should be well addressed.

The matric suction of unsaturated soils has nonlinear variations with depth that is highly dependent on the soil characteristics and different environmental conditions. This study merely addresses uniform and linear suction profiles, and nonlinear profiles of matric suction versus the depth to develop an accurate and general framework for calculating the ultimate bearing capacity of strip foundations will be implemented in future works. On the other hand, this paper mainly conducts theoretical research studies on the design of strip foundations considering the effect of matric suction. Although some simplified assumptions are made, it is useful for many readers and researchers due to the fact that closed-form equations of the ultimate bearing capacity concerning the intermediate principal stress effect and strength nonlinearity are obtained. The finite element analysis, laboratory model tests, and in situ investigations will be performed in future studies. 


\section{Data Availability}

The data used to support the findings of this study are available from the corresponding author upon request.

\section{Conflicts of Interest}

The authors declare that there are no conflicts of interest regarding the publication of this paper.

\section{Acknowledgments}

The financial supports provided by the National Natural Science Foundation of China (NSFC) (Grant nos. 51878056 and 41202191), the Opening Fund of State Key Laboratory of Geohazard Prevention and Geoenvironment Protection (Grant no. SKLGP2020K022), the Fundamental Research Funds for the Central Universities, and CHD (Grant nos. 300102289720 and 300102280108) are gratefully acknowledged.

\section{References}

[1] K. Terzaghi, Theoretical Soil Mechanics, John Wiley \& Sons, New York, NY, USA, 1943.

[2] G. G. Meyerhof, "The ultimate bearing capacity of foudations," Géotechnique, vol. 2, no. 4, pp. 301-332, 1951.

[3] A. S. Vesic, "Analysis of ultimate loads of shallow foundations," Journal of the Soil Mechanics and Foundations Division, vol. 99, no. 1, pp. 45-73, 1973.

[4] V. Silvestri, "A limit equilibrium solution for bearing capacity of strip foundations on sand," Canadian Geotechnical Journal, vol. 40, no. 2, pp. 351-361, 2003.

[5] C. C. Smith, "Complete limiting stress solutions for the bearing capacity of strip footings on a Mohr-Coulomb soil," Géotechnique, vol. 55, no. 8, pp. 607-612, 2005.

[6] D. Chakraborty and J. Kumar, "Bearing capacity of strip foundations in reinforced soils," International Journal of Geomechanics, vol. 14, no. 1, pp. 45-58, 2014.

[7] M. Hamlaoui, A. Oueslati, B. Lamri, and G. de Saxcé, "Finite element analysis of the plastic limit load and the collapse mechanism of strip foundations with non-associated Drucker-Prager model," European Journal of Environmental and Civil Engineering, vol. 19, no. 10, pp. 1179-1201, 2015.

[8] A. Mohebkhah, "Bearing capacity of strip footings on a stone masonry trench in clay," Geomechanics and Engineering, vol. 13, no. 2, pp. 255-267, 2017.

[9] D. G. Fredlund and H. Rahardjo, Soil Mechanics for Unsaturated Soils, John Wiley \& Sons, New York, NY, USA, 1993.

[10] N. Lu and W. J. Likos, Unsaturated Soil Mechanics, John Wiley \& Sons, New York, NY, USA, 2004.

[11] H. D. Lin, C. C. Wang, and X. H. Wang, "A simplified method to estimate the total cohesion of unsaturated soil using an UC test," Geomechanics and Engineering, vol. 16, no. 6, pp. 599-608, 2018.

[12] Y. Tang, H. Vo, H. A. Taiebat, and A. R. Russell, "Influences of suction on plate load tests on unsaturated silty sands," Journal of Geotechnical and Geoenvironmental Engineering, vol. 144, no. 8, Article ID 04018043, 2018.

[13] L. Z. Wu, A. P. S. Selvadurai, L. M. Zhang, R. Q. Huang, and J. Huang, "Poro-mechanical coupling influences on potential for rainfall-induced shallow landslides in unsaturated soils," Advances in Water Resources, vol. 98, pp. 114-121, 2016.
[14] L. Z. Wu, Y. Zhou, P. Sun, J. S. Shi, G. G. Liu, and L. Y. Bai, "Laboratory characterization of rainfall-induced loess slope failure," Catena, vol. 150, pp. 1-8, 2017.

[15] W. T. Oh and S. Vanapalli, "Undrained shear strength of unsaturated soils under zero or low confining pressures in the vadose zone," Vadose Zone Journal, vol. 17, no. 1, Article ID 180024, 2018.

[16] C. Zhang, B. Gao, Q. Yan, J. Zhao, and L. Wu, “Development of allowable bearing capacity for strip foundations in unsaturated soils," Computers and Geotechnics, vol. 114, Article ID 103138, 2019.

[17] L. Z. Wu, J. Huang, W. Fan, and X. Li, "Hydro-mechanical coupling in unsaturated soils covering a non-deformable structure," Computers and Geotechnics, vol. 117, Article ID 103287, 2020.

[18] S. Y. Oloo, D. G. Fredlund, and J. K.-M. Gan, "Bearing capacity of unpaved roads," Canadian Geotechnical Journal, vol. 34, no. 3, pp. 398-407, 1997.

[19] S. K. Vanapalli and F. M. O. Mohamed, "Bearing capacity of model footings in unsaturated soils," Experimental Unsaturated Soil Mechanics, pp. 483-493, Springer-Verlag Press, Berlin, Germany, 2007.

[20] L. H. Zhao, L. Li, F. Yang, Q. Luo, H. C. Dan, and J. F. Zou, "Ultimate bearing capacity calculation of strip foundation on unsaturated soil with upper bound theorem and SQP method," Chinese Journal of Rock Mechanics and Engineering, vol. 28, no. 1, pp. 3021-3028, 2009, in Chinese.

[21] W. T. Oh and S. K. Vanapalli, "Interpretation of the bearing capacity of unsaturated fine-grained soil using the modified effective and the modified total stress approaches," International Journal of Geomechanics, vol. 13, no. 6, pp. 769-778, 2013.

[22] W. T. Oh and S. K. Vanapalli, "Modeling the stress versus settlement behavior of shallow foundations in unsaturated cohesive soils extending the modified total stress approach," Soils and Foundations, vol. 58, no. 2, pp. 382-397, 2018.

[23] T. Vo and A. R. Russell, "Bearing capacity of strip footings on unsaturated soils by the slip line theory," Computers and Geotechnics, vol. 74, pp. 122-131, 2016.

[24] Y. Tang, H. A. Taiebat, and K. Senetakis, "Effective stress based bearing capacity equations for shallow foundations on unsaturated soils," Journal of GeoEngineering, vol. 12, no. 2, pp. 59-64, 2017.

[25] V. Mahmoudabadi and N. Ravichandran, "Design of shallow foundation considering site-specific rainfall and water table data: theoretical framework and application," International Journal of Geomechanics, vol. 19, no. 7, Article ID 04019063, 2019.

[26] A. A. Garakani, H. Sadeghi, S. Saheb, and A. Lamei, "Bearing capacity of shallow foundations on unsaturated soils: analytical approach with 3D numerical simulations and experimental validations," International Journal of Geomechanics, vol. 20, no. 3, Article ID 04019181, 2020.

[27] H. Matsuoka, D. a. Sun, A. Kogane, N. Fukuzawa, and W. Ichihara, "Stress-strain behaviour of unsaturated soil in true triaxial tests," Canadian Geotechnical Journal, vol. 39, no. 3, pp. 608-619, 2002.

[28] L. R. Hoyos, D. D. Pérez-Ruiz, and A. J. Puppala, "Modeling unsaturated soil response under suction-controlled true triaxial stress paths," International Journal of Geomechanics, vol. 12, no. 3, pp. 292-308, 2012.

[29] E. E. Alonso, A. Gens, and A. Josa, "A constitutive model for partially saturated soils," Géotechnique, vol. 40, no. 3, pp. 405-430, 1990. 
[30] M. H. Yu, Unified Strength Theory and its Applications, Springer \& Verlag, Berlin, Germany, 2004.

[31] C. Zhang, X. Chen, W. Fan, and J. Zhao, "A new unified failure criterion for unsaturated soils," Environmental Earth Sciences, vol. 74, no. 4, pp. 3345-3356, 2015.

[32] Z. Y. Ma, H. J. Liao, and F. N. Dang, "Influence of intermediate principal stress on the bearing capacity of strip and circular footings," Journal of Engineering Mechanics, vol. 140, no. 7, Article ID 04014041, 2014.

[33] J. F. Zou and Z. Q. Xia, "Closed-form solution for cavity expansion in strain-softening and undrained soil mass based on the unified strength failure criterion," International Journal of Geomechanics, vol. 17, no. 9, Article ID 04017046, 2017.

[34] L. S. Deng, W. Fan, B. Yu, and Y. Wang, "Influence of the unified strength theory parameters on the failure characteristics and bearing capacity of sand foundation acted by a shallow strip footing," Advances in Mechanical Engineering, vol. 12, no. 2, pp. 1-13, 2020.

[35] D. G. Fredlund, N. R. Morgenstern, and R. A. Widger, "The shear strength of unsaturated soils," Canadian Geotechnical Journal, vol. 15, no. 3, pp. 313-321, 1978.

[36] C. G. Zhang, J. H. Zhao, Q. H. Zhang, and F. Xu, "Unified solutions for unsaturated soil shear strength and active earth pressure," "Unified solutions for unsaturated soil shear strength and active earth pressure," in Proceedings of the GeoShanghai 2010-Experimental and Applied Modeling of Unsaturated Soils (GSP 202), R. L. Hoyos, X. Zhang, and A. J. Puppala, Eds., pp. 218-224, Shanghai, China, June 2010.

[37] C. G. Zhang, Y. S. Hu, and J. H. Zhao, "Unified solution of shear strength for unsaturated soil under plane strain condition and its application," Chinese Journal of Geotechnical Engineering, vol. 33, no. 1, pp. 32-37, 2011, in Chinese.

[38] L. David Suits, T. C. Sheahan, D. W. Rassam, and F. Cook, "Predicting the shear strength envelope of unsaturated soils," Geotechnical Testing Journal, vol. 25, no. 2, pp. 215-220, 2002.

[39] S. L. Houston, N. Perez-Garcia, and W. N. Houston, "Shear strength and shear-induced volume change behavior of unsaturated soils from a triaxial test program," Journal of Geotechnical and Geoenvironmental Engineering, vol. 134, no. 11, pp. 1619-1632, 2008.

[40] C. G. Zhang, X. D. Chen, and W. Fan, "Critical embedment depth of a rigid retaining wall against overturning in unsaturated soils considering intermediate principal stress and strength nonlinearity," Journal of Central South University, vol. 23, no. 4, pp. 944-954, 2016.

[41] C. W. W. Ng, H. Sadeghi, and F. Jafarzadeh, "Compression and shear strength characteristics of compacted loess at high suctions," Canadian Geotechnical Journal, vol. 54, no. 5, pp. 690-699, 2017.

[42] U. D. Patil, L. R. Hoyos, and A. J. Puppala, "“Characterization of compacted silty sand using a double-walled triaxial cell with fully automated relative-humidity control," Geotechnical Testing Journal, vol. 39, no. 5, pp. 742-756, 2016.

[43] U. D. Patil, A. J. Puppala, L. R. Hoyos, and A. Pedarla, "Modeling critical-state shear strength behavior of compacted silty sand via suction-controlled triaxial testing," Engineering Geology, vol. 231, pp. 21-33, 2017.

[44] W. Fan, X. Y. Bai, and M. H. Yu, "Formula of ultimate bearing capacity of shallow foundation based on unified strength theory," Rock and Soil Mechanics, vol. 26, no. 10, pp. 16171622, 2005, in Chinese.

[45] F. Vahedifard and J. D. Robinson, "Unified method for estimating the ultimate bearing capacity of shallow foundations in variably saturated soils under steady flow," Journal of Geotechnical and Geoenvironmental Engineering, vol. 142, no. 4, Article ID 04015095, 2016. 